\title{
Effect of Nursing Intervention on Outcomes for cirrhotic Patients Receiving Direct Acting Antiviral Drugs
}

\author{
Nahla E. Abd Elmonem, Saad Z. Mahmoud, Mogedda M. Mehany \& Asmaa A. Mahgoub. \\ Clinical Nurse Specialist at the Unit of Treatment of Viral Hepatitis, Ministry of Health, Egypt. \\ Professor of Tropical Medicine and Gastroenterology, Faculty of Medicine, Assiut University Egypt. \\ Assistant Professor of Critical Care Nursing, Faculty of Nursing, Assiut University, Egypt. \\ Lecturer of Critical Care Nursing, Faculty of Nursing, Assiut University, Egypt.
}

\begin{abstract}
Background: In the era of Direct Acting Antiviral Drugs (DAAs) for Hepatitis C virus (HCV) management, nursing role and their effect on outcome is still underestimated. Aim of the work: Therefore, this study aimed to evaluate the effect of nursing intervention on outcomes for cirrhotic patients receiving DAAs. Patients and method: Quasi experimental research design was used to conduct this study and designed at the Unit of Treatment of Viral Hepatitis at Assiut Health Directorate to enroll patients with HCV infection and eligible for treatment with DAAs $(n=30)$ and were subjected to nursing knowledge evaluation tools. Two types for tools were applied; Tool (1) patient assessment sheet and Tool (II): (Nursing intervention sheet). Another control group $(n=30)$. Tools were applied in 3 phases; preparatory, implementation and evaluation phase, both pretreatment and post treatment over a six months period. Results: the majority of patients of both study groups were males, farmers, illiterate, and came from rural areas with statistically significant difference. The majority of study group $(96.6 \%)$ had unsatisfactory knowledge scores regarding knowledge of hepatitis $\mathrm{C}$, nutrition and treatment, while $(67.6 \%)$ had satisfactory after implementation of the nursing intervention. Conclusion: The nursing intervention had statistically significant beneficial effects on improving patient's outcomes Recommendation: Providing training program and replication of this study on larger probability sample is highly recommended.
\end{abstract}

Keywords: Nursing Intervention, Direct Acting Antiviral Drugs, Chronic Hepatitis C\& Patient Outcomes.

\section{Introduction}

Hepatitis $\mathrm{C}$ virus (HCV) infection continues to be an important global health problem and is one of the main causes of chronic liver disease worldwide .It is a hepatotropic viral infection caused by $\mathrm{HCV}$, which is a major causes of cirrhosis, liver failure, hepatocellular carcinoma and the most common indication for liver transplantation (American association for the Study of Liver Diseases AASLD, 2012)

Liver Cirrhosis is considered as one of the major health issues as it is one of the most important causes of death in the world. Liver cirrhosis is also defined as a chronic, progressive disease of the liver characterized by necrosis of liver cell and regeneration; Fibrotic bands of connective tissue that impair the flow of blood and lymph and distort the normal liver structure (Goldberg \& Chopra, 2014).

Decompensated cirrhosis: means that, the liver is extensively scarred and unable to function properly. People with decompensated cirrhosis eventually develop many symptoms and complications that can be life threatening as bleeding esophageal or gastric varices, hepatic encephalopathy, hepatorenal syndrome and HCC (Christopher, 2011). In general, every patient with $\mathrm{HCV}$ infection should receive antiviral therapy, because patients who are cured of their HCV infection will benefit with reduction in the risk of liver -related morbidity and mortality (Alan, 2015).

Treatment of HCV infection has 2 goals. The first is to cure $\mathrm{HCV}$ via a sustained elimination of the virus; sustained elimination of HCV is achieved if Polymers Chain Reaction (PCR) remains negative six month after the end of treatment sustained virolgical response SVR. The infection is cured in more than 99\% of patients who achieve an SVR. The SVR is generally associated with resolution of liver disease in patients without cirrhosis. The second goal is to prevent progression to cirrhosis, HCC, and decompensated a liver disease which requires liver transplantation. Recent data suggest that the risk of HCC and all-cause mortality is significantly reduced, but not eliminated, in cirrhotic patients who clear $\mathrm{HCV}$ compared to untreated patients and those without sustained virological responders. (Van der Meer, et al., (2012).

The development of the direct acting antiviral drugs (DAAs) for treatment of $\mathrm{CHC}$ represent major advance in this issue. These new agents have high efficacy rates, short treatment duration, and minimal tolerable adverse effects. The development of these DAAs has rapidly evolved over the past 5 years and has radically changed the HCV treatment paradigm to 
allow interferon-free regimens, of which several are now approved and available in clinical practice in many countries (Bartenschlager, et al., 2013).

Critical care nursing today needs to define basic clinical guidelines that are needed not only to define what constitutes safe practice, but also to guide nurse's decision making. Good clinical guidelines can change the process of health care and improve patient $\mathrm{s}$ outcomes.in addition; clinical guidelines can be used as educational and training tools for the critical care nurses (World Health Organization , 2012).

Operational definition of outcomes

Outcome for patients who are receiving DAAs for $\mathrm{CHC}$ is intended to improve the patient's management from the diagnosis to end of the course of antiviral therapy and during follow up. This includes maintaining physical activity, recognizing activity limitations, following dietary modifications, maintaining adequate nutrition, preventing complications, enhancing self-concept, and accepting the situation .

\section{Significance of the study}

Liver cirrhosis is considered a health problem in various countries and regions, in the USA every year, complications from cirrhosis lead to over 400,000 hospitalizations and 27,000 deaths. In Egypt, 76.92\% of patients admitted to the National Liver Institute Hospital for treatment at in-patient department had liver cirrhosis (Centers for Disease Control \& Prevention, 2014).

Nurse play role in the patient educator, hence this study aimed to evaluate the effect of nursing intervention on outcome for patient receiving direct acting antiviral drugs for treatment of chronic hepatitis $\mathrm{C}$.

\section{Aim of the study}

This study aimed to evaluate the effect of nursing intervention on outcomes for patients receiving direct acting antiviral drugs for treatment of chronic

hepatitis C.

\section{Research Hypothesis}

1.Patients of study group who receiving nursing intervention have good outcomes rather than control group.

2. Statistically significant difference between two group regarding patient's knowledge about information of hepatitis (c) and liver cirrhosis

\section{Patients and methods}

\section{Research design}

Quasi -experimental research design was used to conduct this study

\section{Setting}

The study was carried out at the Unit of Treatment of Viral Hepatitis at Assuit Health Directorate.

\section{Sample}

A convenient sample of 60 patients with $\mathrm{HCV}$ related liver cirrhosis that was under treatment with DAAs based regimen was included in this study. They were divided into two groups; study group (30 patients) who were receiving nursing intervention and control group (30 patients) who were exposed to the routine care in the unit.

\section{Inclusion criteria}

Patients with liver cirrhosis caused by $\mathrm{CHC}$ who were diagnosed according to the following criteria:

- Clinical criteria: known clinical criteria of liver cirrhosis as firm reduced or enlarged liver with sharp border, splenomegaly, spider naevi and other manifestations of liver cell failure (ascites esophageal varices).

- Abdominal ultrasonography: coarse echo pattern, reduced size with or without irregular surface and splenomegaly.

- Laboratory investigations including prolonged prothrombin time low serum albumin with or without raised ALT and AST.

- Fibro scan (transient electrography) reading from $15.7 \mathrm{k}$ Pascal and above correlates with fibrosis stage 4 (F4) on the Metavir score of fibrosis staging.

- Patients with advanced liver disease (child score $\geq$ 8) according to update protocol of National committee for control of viral hepatitis NCCVH.

- Age above 18 years and under 60 years.

Exclusion criteria

- Fibro scan (transient electrography) reading from 0-15.0 k Pascal and with fibrosis stage 0-3 (F0-F1F2-F3) on the Metavir score of fibrosis staging.

- Patients with advanced liver disease (child score $\leq$ 8).

- Patients with hepatic encephalopathy and severe ascites.

\section{Tools}

The following two tools were utilized to collect data in this study. They were developed by the researchers after extensive review of the relevant literature.

Tool (1) patients assessment sheet: to assess patient's medical and laboratory data and consists of four parts:

Part 1- Sociodemographic and medical data:

- Sociodemographic data include: patient's code, age, sex, residence telephone number, marital status, level of education, and occupation.

- Medical data: past and present history of any other disease, medications for other diseases, family history, date of first visit to unit, follow up, circumstances of referral and allergy for any medication. 
Part 2- History and clinical examination assessment sheet:

This part was concerned to

- Assess for history of previous liver diseases, presence of genetic and metabolic diseases affecting liver.

Obtain history of onset and progression of symptoms.

- Collect information from patient such as (jaundice, abdominal pain, nausea, vomiting, bowel disturbances, fever, appetite changes, neurological changes, changes in color of urine and stool, etc.).

- Perform complete physical assessment including vital signs, signs of liver damage, jaundice, bowel dysfunction, encephalopathy, and ascites.

Part 3- Laboratory and imaging assessment sheet:

It included fasting blood sugar and $\mathrm{HbA}_{1} \mathrm{c}$ in diabetic patient, ,kidney function tests (S.urea Creatinine ), liver function tests (ALT -AST prothrombin time and concentration -total and indirect bilirubin - s.albumin ),complete blood picture and baseline level of viremia HCV using polymerase chain reaction (PCR), AFP, Imaging assessment: including abdominal ultrasonography and fibro scan.

Part4 -Child-Turcotte-Pugh -score

This score adopted from (Friedman, 2012) .The Child-Pugh Score is a scoring system used to determine the prognosis of cirrhosis. This part was concerned to assess the severity of the disease and predict mortality in patients with liver cirrhosis. This score include three biochemical markers (serum albumin, total bilirubin, and prothrombin time, INR) and clinical features as the presence of ascites and hepatic encephalopathy. The Child score ranges from 5-15 with individual scoring 5-6 being class A, 7-9 are being class B and 10-15 class C. As mention in interpretation in the following table

Tool (II): Nursing intervention about disease and drugs: includes two parts:

Part 1- Nursing intervention which includes instructions related to liver cirrhosis and its complications.

Part 2- Nursing intervention which include instructions related to direct acting antiviral drugs for treatment of chronic hepatitis $\mathrm{C}$ including name, action, dose, route of administration and frequency, side effects of the drug and nursing precaution for each type of drugs.
Table (1) : Child-Turcotte-Pugh (CTP) classification of the severity of cirrhosis Child-Turcotte-Pugh Classification for Severity of Cirrhosis

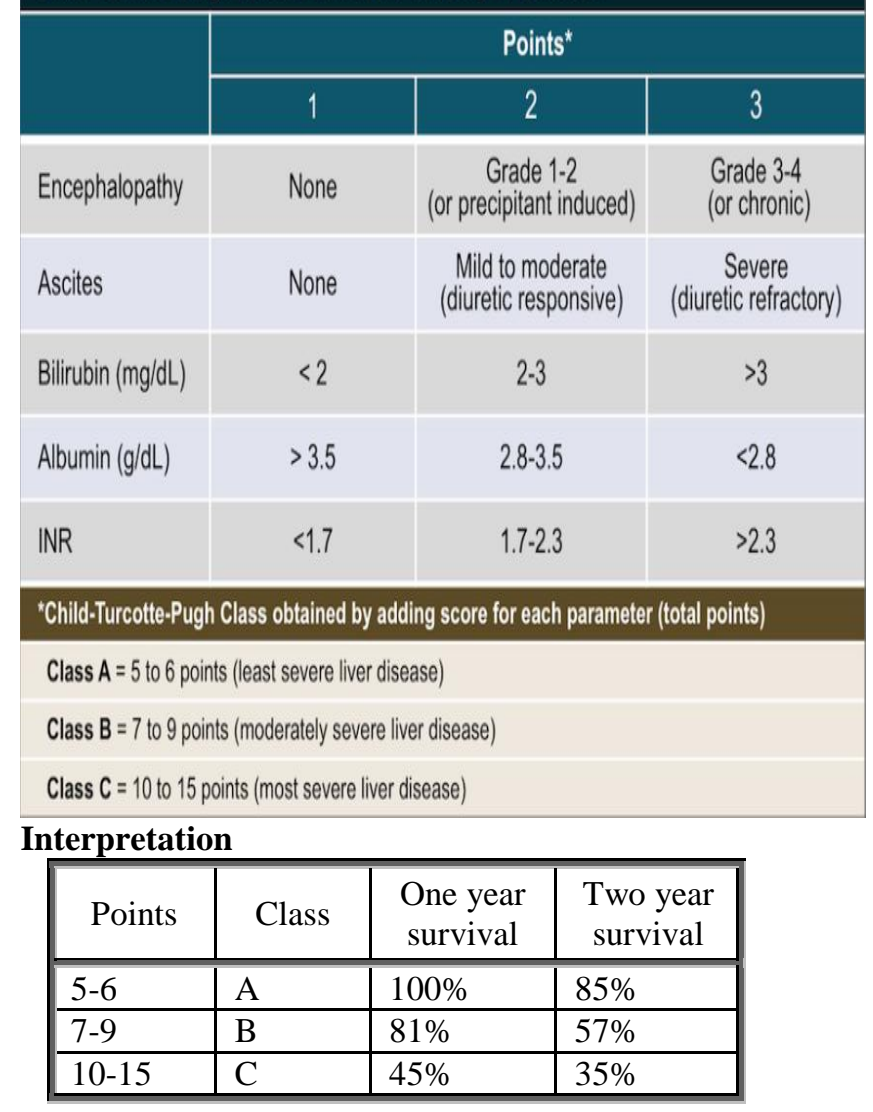

\section{Methods}

The study was conducted throughout three main phases which are preparatory phase, implementation phase and evaluation phase.

\section{Preparatory phase}

- An official permission was obtained from Dean of the Faculty of Nursing Assuit University and head of Unit of Treatment of Viral Hepatitis at Assuit Health Directorate to collect the necessary data after explain the purpose and nature of the study.

- The tool was developed by the researcher based on reviewing of current international related literature in the various aspects of the problems using text books, articles, different studies, internet and Journals

- Content validity of tools: The tools were tested for content validity by jury of 5 experts in the field of critical care nursing and Tropical Medicine and Gastroenterology at Assuit University and the necessary modifications were done.

- Reliability was estimated by Cronbach's Alpha for tool 1 liver assessment sheet and its result was 0.79, for tool 2 nursing interventions about disease 
and drugs and its result was0.87which were accepted.

- The pilot study: Pilot study was carried out on $10 \%$ of study sample who met the predetermined selection criteria to test applicability of the tools then necessary modifications were done according to the results of the pilot study and expertise opinions. The participants of pilot study were excluded from the study.

\section{Ethical consideration}

- Research proposal was approved by ethical committee of the faculty of nursing .

- Informed consent was taken from patient participating study, after explaining the nature and purpose of the study.

- Confidentiality and anonymity were being assured.

- Patients were assured that, the data of his research will not be refused without second permission.

- Patients were informed that they refuse to participate and or withdraw from the study without any rational any time.

Implementation phase

This phase was involved :( for both groups)

- The study was carried out during morning in the unit, when patients visit to unit.

- The patients admitted early in the morning at 9:00 at unit

- Patient comes to the unit every month at the first 3 month for those who received 3 month regimen and for other 3 month for follow up.

- The researcher explaining the purpose of the study to Patient when coming to receive drug from unit.

- The researcher filled out sheet through interviewing each patient individually to obtain the necessary information.

- The average of time taken for completing each tool was around 5-10 minutes depending on the patient's responses to question.

- Data was collected about 2-3 participant per day started from May, 2016 to end of October, 2016.

- Study and control groups were received the routine care in the unit where assessed by the researcher using first tool (liver assessment sheet).

- Routine care include assess vital signs (temperature, blood pressure, plus) weight and height, Perform physical examination (jaundice, palmer erythema ,tremors ,white nails ,ascites , bruises, scratch marks, Spider naevi, splenomegaly, Lower limb edema, Degree of edema ), Perform abdominal ultrasound and assess laboratory investigation ( fasting blood sugar and HbA1c if patient was diabetic, kidney function tests (Albumin - Creatinine ), liver function tests (ALT -AST -, prothrombin time and concentration and total and indirect bilirubin),complete blood picture $\mathrm{CBC},(\mathrm{PCR})$ quantitative ,AFP at week(16-24) only and fibro scan

(transient electrography) at start of treatment and end of treatment , Performed Child -turcotte -Pugh (CTP) scoring system.

\section{For Study group}

Introduced nursing intervention inform nursing booklet which include

Knowledge about Chronic Hepatitis $\mathrm{C}$ and its sequelae

- The hepatitis $\mathrm{C}$ virus can cause both acute and chronic hepatitis infection, ranging in severity from a mild illness lasting a few weeks to a serious, lifelong illness.

- The hepatitis $\mathrm{C}$ virus is a blood borne virus. It is most commonly transmitted mostly through transfusion of unscreened blood and blood products, injecting drug use through the sharing of injection equipment, in health care settings due to the inadequate sterilization of medical equipment, especially syringes and needles

- Hepatitis C is not transmitted through breast milk, food or water or by casual contact such as hugging, kissing and sharing food or drinks with an infected person.

- There is currently no vaccine for hepatitis $\mathrm{C}$.

- Chronic hepatitis $\mathrm{C}$ infection can take up to 20 -25 years to progress to cirrhosis, liver cell failure or hepatocellular carcinoma.

- Cirrhosis is divided into two categories:

a) Compensated liver cirrhosis: means that the liver is heavily scarred but can still perform many important bodily functions

b) Decompensated liver cirrhosis: means that the liver is extensively scarred and unable to function probably.

- Cirrhosis may present with vague symptoms such as fatigue, malaise, anorexia, and nausea and weight loss nausea and weight loss. In advanced decompensated liver disease, presentation may include: edema, ascites, bleeding esophageal varices, poor concentration and memory.

Instructions related to treatment of $\mathrm{CHC}$ :

- The goal of HCV treatment is to eradicate the virus and prevent the development of cirrhosis and its complications such as portal hypertension, hepatocellular failure and hepatocellular carcinoma.

- Treatment regimen contains three oral drugs sofosbuvir, daclatasvir and ribavirin. The duration of treatment is 12 weeks. The success rate of the treatment may reach 97\%.Ensure adequate nutrition, including calorie and protein intake. 
Sofosbuvir: - It is tablet form, each contains $400 \mathrm{mg}$ : - It should be taken before breakfast at the same time each day- If vomiting occurs after taking the drug by less than 2 hours you should take another tablet.

If you missed one tablet within 18 hours you should take it, but if you remembered after 18 hours take the tablet in the next day but never take double dose.

\section{Daclatasvir}

-It is a tablet form; each contains $60 \mathrm{mg}$. -It should be taken with or without food at the same time each day.

\section{Ribavirin}

Ribavirin can also cause birth defects, so it should not be used by pregnant women and woman must receive contraception if her husband is using ribavirin and up to 6 months after stop of ribavirin.

\section{Instructions related Side effect of drugs}

- The patient may experience one or more of the following side effects of the antiviral drugs: chest pain, headache, itching, fatigue, and tiredness, loss of appetite, nausea, insomnia mild diarrhea, dry skin, fever, mode change, throat Irritation, arthralgia, and myalgia, cough, and dizziness, bradycardia and memory problems.

- The patient must be asked to contact us by phone or during visits by if any of these side effects occurred to assure the patient and deal with these side effects.

- The patient may experience changes in laboratory investigation especially anemia, total and differential bilirubin elevation that may need correction and precautions.

Instructions related to follow up

- Contact the patients regularly or when the patient needs by phone or directly to assure the patient , ensure medication adherence, ask about any side effects, any old or new drugs used by the patients to advise about drug-drug interactions.

- Ask the patients to do CBC and liver function tests every month.

- Ask the patients to do quantitative PCR at end of treatment week (after week 12) and 3 month after stop of treatment.

- SVR means undetectable HCV RNA by PCR 3 month after stop of treatment and means cure from the virus.

\section{Evaluation phase}

Study and control groups were followed up monthly for 6 months to evaluate effects of nursing intervention on patient's outcomes and to insist on participant's compliance to the given instructions by using tool (1).

\section{Statistical Analysis}

All the statistical analysis was performed using SPSS package version 20 . The collected data were coded and analyzed. Data were presented using descriptive statistics in the form of frequencies and percentages for qualitative variables and mean and standard deviations for quantitative variables. Qualitative variables were compared using Chi-square and ANOVA tests. Spearman correlation coefficient test was used to test correlation between variables. Statistical significance was considered at P. value < 0.05 . 


\section{Results}

Table (1): Socio-demographic characteristics of the studied subjects at the Unit of Treatment of Viral Hepatitis inAssuit city 2016.

\begin{tabular}{|c|c|c|c|c|c|}
\hline \multirow[t]{2}{*}{ Socio-demographic characteristics } & \multicolumn{2}{|c|}{$\begin{array}{r}\text { Study group } \\
(\mathrm{n}=\mathbf{3 0})\end{array}$} & \multicolumn{2}{|c|}{$\begin{array}{r}\text { Control group } \\
(\mathrm{n}=\mathbf{3 0})\end{array}$} & \multirow[t]{2}{*}{ P-value } \\
\hline & No. & $\%$ & No. & $\%$ & \\
\hline \multicolumn{5}{|l|}{ Sex } & \multirow{3}{*}{$0.791^{\mathrm{ns}}$} \\
\hline Male & 19 & 63.3 & 18 & 60.0 & \\
\hline Female & 11 & 36.7 & 12 & 40.0 & \\
\hline \multicolumn{5}{|l|}{ Age: (years) } & \multirow{4}{*}{$0.380^{\mathrm{ns}}$} \\
\hline$<40$ & 1 & 3.3 & 1 & 3.3 & \\
\hline $40-<50$ & 7 & 23.3 & 3 & 10.0 & \\
\hline$\geq 50$ & 22 & 73.3 & 26 & 86.7 & \\
\hline Mean \pm SD & \multicolumn{2}{|c|}{$54.63 \pm 7.06$} & \multicolumn{2}{|c|}{$55.60 \pm 7.58$} & $0.611^{\mathrm{ns}}$ \\
\hline Range & \multicolumn{2}{|c|}{$38.0-66.0$} & \multicolumn{2}{|c|}{$38.0-66.0$} & \\
\hline \multicolumn{5}{|l|}{ Residence } & \multirow{3}{*}{$0.739^{\mathrm{ns}}$} \\
\hline Rural & 25 & 83.3 & 24 & 80.0 & \\
\hline Urban & 5 & 16.7 & 6 & 20.0 & \\
\hline \multicolumn{5}{|l|}{ Occupation } & \multirow{7}{*}{$0.429^{\mathrm{ns}}$} \\
\hline Farmer & 11 & 36.7 & 7 & 23.3 & \\
\hline Government employee & 4 & 13.3 & 7 & 23.3 & \\
\hline Private sector employee & 0 & 0.0 & 2 & 6.7 & \\
\hline Skilled worker & 3 & 10.0 & 4 & 13.3 & \\
\hline Unskilled worker & 1 & 3.3 & 0 & 0.0 & \\
\hline Housewife & 11 & 36.7 & 10 & 33.3 & \\
\hline \multicolumn{5}{|l|}{ Education } & \multirow{7}{*}{$0.330^{\mathrm{ns}}$} \\
\hline Illiterate & 14 & 46.7 & 10 & 33.3 & \\
\hline Read \& write & 6 & 20.0 & 7 & 23.3 & \\
\hline Primary & 4 & 13.3 & 5 & 16.7 & \\
\hline Preparatory & 3 & 10.0 & 1 & 3.3 & \\
\hline Secondary & 1 & 3.3 & 6 & 20.0 & \\
\hline University & 2 & 6.7 & 1 & 3.3 & \\
\hline
\end{tabular}

$N S=$ no statistical significant difference

Table (2): Distribution of studied subjects regarding abdominal ultrasound at baseline, during treatment, and at the end of treatment

\begin{tabular}{|c|c|c|c|c|c|c|}
\hline \multirow{2}{*}{$\begin{array}{l}\text { abdominal } \\
\text { ultrasound }\end{array}$} & & \multicolumn{2}{|c|}{$\begin{array}{l}\text { Study group } \\
\quad(\mathbf{n}=\mathbf{3 0})\end{array}$} & \multicolumn{2}{|c|}{$\begin{array}{l}\text { Control group } \\
(n=30)\end{array}$} & \multirow[t]{2}{*}{ P-value } \\
\hline & & No. & $\%$ & No. & $\%$ & \\
\hline \multirow{11}{*}{ At baseline: } & Liver & & & & & \\
\hline & Cirrhotic & 30 & 100.0 & 30 & 100.0 & -- \\
\hline & Spleen & & & & & \\
\hline & Enlarged & 30 & 100.0 & 30 & 100.0 & -- \\
\hline & PV & & & & & \\
\hline & Patent & 30 & 100.0 & 30 & 100.0 & -- \\
\hline & Ascites & & & & & \multirow{5}{*}{$0.570^{\mathrm{ns}}$} \\
\hline & Mild & 12 & 40.0 & 12 & 40.0 & \\
\hline & Moderate & 3 & 10.0 & 1 & 3.3 & \\
\hline & No & 15 & 50.0 & 17 & 56.7 & \\
\hline & Focal lesion & - & - & - & - & \\
\hline
\end{tabular}




\begin{tabular}{|c|c|c|c|c|c|c|}
\hline \multirow{2}{*}{$\begin{array}{l}\text { abdominal } \\
\text { ultrasound }\end{array}$} & & \multicolumn{2}{|c|}{$\begin{array}{l}\text { Study group } \\
\quad(n=30)\end{array}$} & \multicolumn{2}{|c|}{$\begin{array}{c}\text { Control group } \\
(n=30)\end{array}$} & \multirow[t]{2}{*}{ P-value } \\
\hline & & No. & $\%$ & No. & $\%$ & \\
\hline \multirow{11}{*}{ During treatment } & Liver & & & & & \\
\hline & Cirrhotic & 30 & 100.0 & 30 & 100.0 & -- \\
\hline & Spleen & & & & & \\
\hline & Enlarged & 30 & 100.0 & 30 & 100.0 & -- \\
\hline & $\mathbf{P V}$ & & & & & \\
\hline & Patent & 30 & 100.0 & 30 & 100.0 & -- \\
\hline & Ascites & & & & & \multirow{5}{*}{--} \\
\hline & Mild & 10 & 33.3 & 10 & 33.3 & \\
\hline & Moderate & 1 & 3.3 & 1 & 3.3 & \\
\hline & No & 19 & 63.3 & 19 & 63.3 & \\
\hline & Focal lesion & - & - & - & - & \\
\hline \multirow{11}{*}{$\begin{array}{l}\text { At the end of } \\
\text { treatment }\end{array}$} & Liver & & & & & \\
\hline & Cirrhotic & 30 & 100.0 & 30 & 100.0 & -- \\
\hline & Spleen & & & & & \\
\hline & Enlarged & 30 & 100.0 & 30 & 100.0 & -- \\
\hline & $\mathbf{P V}$ & & & & & \\
\hline & Patent & 30 & 100.0 & 30 & 100.0 & -- \\
\hline & Ascites & & & & & \multirow{5}{*}{$0.589^{\mathrm{ns}}$} \\
\hline & Mild & 8 & 26.7 & 9 & 30.0 & \\
\hline & Moderate & 1 & 3.3 & 0 & 0.0 & \\
\hline & No & 21 & 70.0 & 21 & 70.0 & \\
\hline & Focal lesion & - & - & - & - & \\
\hline
\end{tabular}

Table (3): Distribution of studied subjects regarding liver function test at baseline, during treatment, and at the end of treatment.

\begin{tabular}{|c|c|c|c|}
\hline \multirow[t]{2}{*}{ liver function test } & $\begin{array}{c}\text { Study group } \\
(\mathbf{n = 3 0 )}\end{array}$ & $\begin{array}{c}\text { Control group } \\
(n=30)\end{array}$ & \multirow[t]{2}{*}{ P-value } \\
\hline & Mean \pm SD & Mean \pm SD & \\
\hline \multicolumn{4}{|l|}{ At baseline } \\
\hline T. bilirubin (mg/dl) & $1.79 \pm 0.83$ & $1.52 \pm 0.75$ & $0.198^{\mathrm{ns}}$ \\
\hline Indirect bilirubin $(\mathrm{mg} / \mathrm{dl})$ & $1.10 \pm 0.53$ & $0.97 \pm 0.54$ & $0.361^{\mathrm{ns}}$ \\
\hline $\operatorname{ALT}(\mathrm{u} / \mathrm{l})$ & $61.33 \pm 31.12$ & $70.86 \pm 50.97$ & $0.386^{\mathrm{ns}}$ \\
\hline $\operatorname{AST}(\mathrm{u} / \mathrm{l})$ & $56.39 \pm 29.12$ & $68.66 \pm 38.32$ & $0.168^{\mathrm{ns}}$ \\
\hline $\mathrm{PT}(\mathrm{sec})$ & $66.13 \pm 16.02$ & $75.40 \pm 16.42$ & $0.031 *$ \\
\hline $\operatorname{INR}(\%)$ & $1.52 \pm 0.43$ & $1.33 \pm 0.26$ & $0.046^{*}$ \\
\hline Albumin (g/dl) & $2.78 \pm 0.37$ & $2.97 \pm 0.38$ & $0.063^{\mathrm{ns}}$ \\
\hline \multicolumn{4}{|l|}{ During treatment: (after 2month) } \\
\hline T. bilirubin $(\mathrm{mg} / \mathrm{dl})$ & $1.36 \pm 0.54$ & $1.31 \pm 0.61$ & $0.720^{\mathrm{ns}}$ \\
\hline Indirect bilirubin $(\mathrm{mg} / \mathrm{dl})$ & $0.72 \pm 0.26$ & $0.78 \pm 0.43$ & $0.493^{\mathrm{ns}}$ \\
\hline $\operatorname{ALT}(\mathrm{u} / \mathrm{l})$ & $36.59 \pm 11.52$ & $38.20 \pm 16.33$ & $0.661^{\mathrm{ns}}$ \\
\hline $\operatorname{AST}(\mathrm{u} / \mathrm{l})$ & $43.32 \pm 10.01$ & $48.43 \pm 21.63$ & $0.245^{\mathrm{ns}}$ \\
\hline PT $($ sec $)$ & $73.77 \pm 9.84$ & $78.63 \pm 13.00$ & $0.107^{\mathrm{ns}}$ \\
\hline INR $(\%)$ & $1.39 \pm 0.44$ & $1.26 \pm 0.24$ & $0.167^{\mathrm{ns}}$ \\
\hline Albumin (g/dl) & $3.18 \pm 0.33$ & $3.21 \pm 0.38$ & $0.771^{\mathrm{ns}}$ \\
\hline \multicolumn{4}{|c|}{ At the end of treatment:(afte 6 month } \\
\hline T. bilirubin $(\mathrm{mg} / \mathrm{dl})$ & $1.32 \pm 0.43$ & $1.29 \pm 0.63$ & $0.813^{\mathrm{ns}}$ \\
\hline Indirect bilirubin $(\mathrm{mg} / \mathrm{dl})$ & $0.68 \pm 0.19$ & $0.70 \pm 0.37$ & $0.826^{\mathrm{ns}}$ \\
\hline $\operatorname{ALT}(\mathrm{u} / \mathrm{l})$ & $39.98 \pm 12.51$ & $43.36 \pm 10.58$ & $0.264^{\mathrm{ns}}$ \\
\hline
\end{tabular}




\begin{tabular}{|l|c|c|c|}
\hline \multirow{2}{*}{\multicolumn{1}{|c|}{ liver function test }} & $\begin{array}{c}\text { Study group } \\
(\mathbf{n = 3 0})\end{array}$ & $\begin{array}{c}\text { Control group } \\
(\mathbf{n}=\mathbf{3 0})\end{array}$ & \multirow{2}{*}{ P-value } \\
\cline { 2 - 3 } & Mean \pm SD & Mean \pm SD & \\
\hline AST $(\mathrm{u} / \mathrm{l})$ & $43.26 \pm 8.94$ & $48.25 \pm 14.18$ & $0.108^{\mathrm{ns}}$ \\
\hline $\mathrm{PT}(\mathrm{sec})$ & $76.03 \pm 8.99$ & $81.27 \pm 11.02$ & $0.049^{*}$ \\
\hline INR $(\%)$ & $1.37 \pm 0.18$ & $1.18 \pm 0.23$ & $0.016^{*}$ \\
\hline Albumin $(\mathrm{g} / \mathrm{dl})$ & $3.33 \pm 0.33$ & $3.45 \pm 0.28$ & 0.118 \\
\hline
\end{tabular}

* Statistically significant differences ( $p<0.05), N S=$ non statistical significant differences, $A L T=$ Alanine

Aminotransferase, $A S T=$ Aspartate Aminotransferase, $P T=$ Prothrombin Time, INR=international normalized ratio

Table (4): Distribution of studied subjects regarding PCR Quantitative at before, at end of and after3 month of treatment

\begin{tabular}{|c|c|c|c|c|c|}
\hline \multirow{2}{*}{ PCR quantitative } & \multicolumn{2}{|c|}{ Study group $(n=30)$} & \multicolumn{2}{|c|}{ Control group $(\mathrm{n}=30)$} & \multirow{2}{*}{ P-value } \\
\hline & No. & $\%$ & No. & $\%$ & \\
\hline \multicolumn{5}{|l|}{ Before treatment } & \multirow{3}{*}{--} \\
\hline Positive & 30 & 100.0 & 30 & 100.0 & \\
\hline Negative & 0 & 0.0 & 0 & 0.0 & \\
\hline \multicolumn{5}{|l|}{ At end of treatment } & \multirow{3}{*}{$0.554^{\mathrm{ns}}$} \\
\hline Non Responder & 1 & 3.3 & 1 & 3.3 & \\
\hline ETR & 29 & 96.7 & 29 & 96.7 & \\
\hline \multicolumn{5}{|c|}{ After end of treatment (3month of the end of treatment) } & \multirow{3}{*}{--} \\
\hline Relapse & 1 & 3.3 & 0 & 0.0 & \\
\hline SVR & 28 & 93.3 & 29 & 96.7 & \\
\hline
\end{tabular}

$N S=$ no statistical significant differences, ETR: End Treatment Response,SVR: sustained virological response

Table (5): Distribution of studied subject regarding Child -Turcotte -Pugh scores at the Unit of Treatment of Viral Hepatitis.

\begin{tabular}{|l|c|c|c|}
\hline \multirow{2}{*}{ Child Score } & $\begin{array}{c}\text { Study group } \\
(\mathbf{n}=\mathbf{3 0})\end{array}$ & $\begin{array}{c}\text { Control group } \\
(\mathbf{n}=\mathbf{3 0})\end{array}$ & \multirow{2}{*}{ P-value } \\
\cline { 2 - 3 } & Mean \pm SD & Mean \pm SD & \\
\hline Week 0 & $6.93 \pm 1.08$ & $8.42 \pm 1.35$ & $0.007^{*}$ \\
\hline Week 4 & $6.93 \pm 1.11$ & $8.13 \pm 1.29$ & $0.006^{*}$ \\
\hline Week 8 & $6.53 \pm 0.82$ & $8.29 \pm 1.06$ & $0.009^{*}$ \\
\hline Week 12 & $6.37 \pm 0.93$ & $7.33 \pm 0.97$ & $0.011^{*}$ \\
\hline Week 16 & $6.30 \pm 0.84$ & $7.27 \pm 0.71$ & $0.015^{*}$ \\
\hline Week 24 & $5.97 \pm 0.93$ & $7.15 \pm 0.83$ & $0.004^{*}$ \\
\hline
\end{tabular}

* Statistically significant differences ( $p<0.05)$.

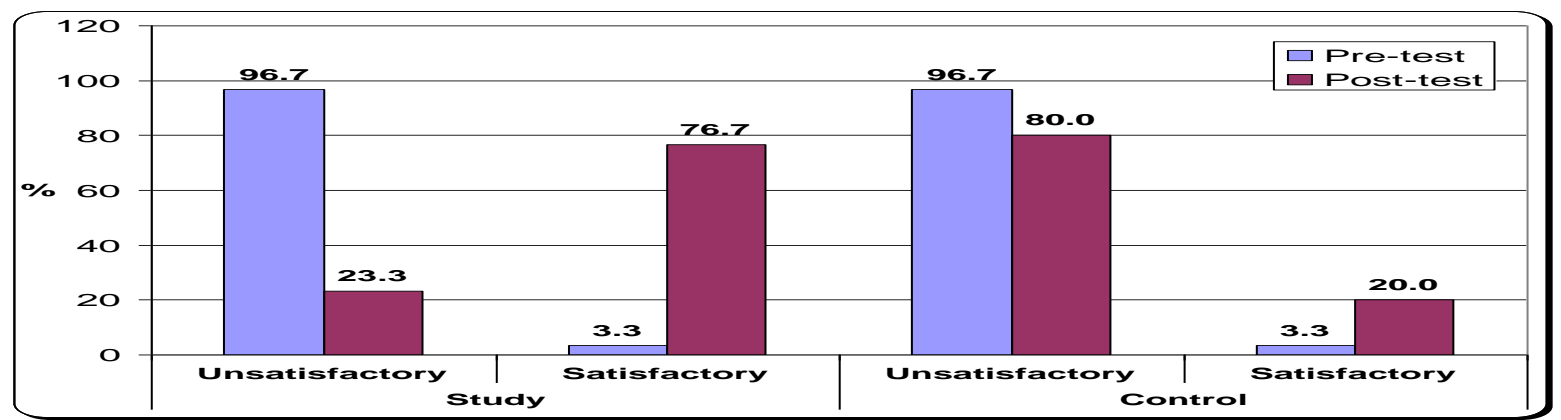

Figure (1 ):comparison between pre-test and post-test in study and control groups regarding Level of knowledge about hepatitis at the Unit of Treatment of Viral Hepatitis in assuit city 2016.

Less than 60\%unsatisfactory

More than or equal $60 \%$ satistfactory 
Table (1): Shows the distribution of the studied subjects regarding socio-demographic characteristics. It shows that; the majority patients of both study and control group were farmer, illiterate, and came from rural areas, study group $(36.7 \%, 46.7 \%, 83.3 \%$ respectively) control group $(23.3 \%, 33.3 \%, 80.0 \%$ respectively) and their age ranged between 38 and 66 years, with mean \pm SD $54.63 \pm 7.06$ years as compared to $55.60 \pm 7.58$ for the control group. The highest percentage of both study and control group patients were males $(63.3 \%, 60.0 \%)$ respectively with statistically significant difference $\mathrm{P}>0.05$.

Table (2): Shows the distribution of the studied subjects regarding abdominal ultrasound at the Unit of Treatment of Viral Hepatitis. It clarifies that all parameters in study and control groups had liver cirrhosis, splenomegaly with patent portal vein at bassline, during and ends of treatment with statistically significant difference $\mathrm{P}>0.05$. Also this table reported that, percentage of study group with ascites at baseline $(40.0 \%)$ while this percentage decline during and at end of treatment $(33.0 \%, 26.0 \%$ respectively).

Table (3): This table reveals distribution of studied subjects regarding liver function tests. It was clarified that statistical significant differences between study and control groups were found regarding prothrombin concentration and INR at baseline, and at end of treatment $(p=0.031, p=0.046$ respectively $),(p=0.049$, $\mathrm{P}=0.016$ respectively), while no statistical significant difference between study and control groups during treatment. $\mathrm{P}>0.05$

Table (4): Reveals the distribution of the studied subjects regarding to quantitative PCR. It shows that PCR for HCV RNA became negative at the end of treatment in $96.7 \%$ of patients in both groups. SVR was achieved in $93.3 \%$ in study group and $96.7 \%$ of control group with statistically significant difference $\mathrm{P}>0.05$.

Table (5) Showed that, all Child -Turcotte -Pugh scores for studied subjects were high statistical significant differences between study and control group from week 0 to week 24 ( $\mathrm{p}=0.007, \mathrm{p}=0.006$, $\mathrm{p}=0.009, \mathrm{P}=0.011, \mathrm{p}=0.015, \mathrm{p}=0.004$ respectively) .

It was observed there were high statistical significant differences between study and control groups regarding Child -Turcotte-Pugh scores.

\section{Discussion}

Hepatitis $\mathrm{C}$ virus infection is one of the main causes of chronic liver disease worldwide. The long-term impact of HCV infection is highly variable, ranging from minimal histologic-all changes to extensive fibrosis and cirrhosis with or without HCC. (HCV) Induced decompensated liver cirrhosis (LC) is a lifethreatening illness with an average 5-year survival rate of $50 \%$. Although liver transplantation has been the only curative therapy for these patients, treatment is important issues where the recently-developed (DAAs) are now helping patients cope with these difficult situations. Because DAAs have far fewer adverse effects and are better tolerated than interferon (IFN), they can be used to treat the elderly or patients with comorbidities (Goldberg \& Chopra, 2014).

The teaching-learning process is considered as means by which the patient can acquire knowledge, skills, and be encouraged to participate in their treatment, making decisions and assuming responsibilities. With the knowledge developed, the patient may change its health behavior (WHO, 2012). Therefore; this study aimed to evaluate the impact of nursing intervention on outcomes among patients receiving DAADs for Treatment of Chronic Hepatitis C.

The results of the present study showed that most of patient's age ranged between 38 and 66 years, with Mean \pm SD $54.63 \pm 7.06$. This finding was higher than the results of Heneedy, (2009) who reported that the mean age of study sample was $49.8 \pm 8$.3for study group and $49.3 \pm 8.7$ years for control group.

As regard to sex, the studied subjects showed that more than half of studied subjects were males followed by less than half of studied subject were females. This finding could be attributed to that more than half of studied subject were males because they are more discovery of the (HCV) through performing investigation for traveling abroad. This was agree with (Alavian, et al., 2010) who reported that more than three fourth of studied subject were male.

According to educational level the present study showed that more than two fifth of patient were Illiterate. This finding could be attributed to that more than two third of studied patients were from rural areas and of low economic status.

Furthermore, the present revealed that all of study patients were having liver cirrhosis, splenomegaly and other manifestations of liver cell failure; ascites was clear that around fifth of them while decline during and at end of treatment to more than one quarter of study group .

Regarding liver function test. It was noticed slightly difference between before, during and at end of treatment. Also the present study showed significant improvement of prothrombin concentration, INR, albumin after application of nursing intervention. This finding could be attributed to side effect of new treatment regimen agent very limited and due to effect of nursing intervention received from unit by the researcher.

In addition, regarding to total Child -Turcotte -Pugh scores the results of the present study showed that high statistical significant improvement between study and control group after application of the 
nursing intervention. Regards correlation between total Child -Turcotte -Pugh scores and age, It reveals that there is no significant influences between age and total Child -Turcotte -Pugh scores. This was in accordance with study of Bifano, (2015) which denoted that study with 108 Child-Pugh B and C patients demonstrated that virological response to SOF/DAC/RBV for 12 weeks was associated with improvements in bilirubin, albumin, and MELD and Child-Pugh scores.

The present study indicated that SVR was for majority of studies subject. This finding could be attributed to SVR rate for (DAAs) treatment (96\%) because the good safety profile of new treatment regimen agent, have high efficacy rates, short treatment duration, and minimal tolerable adverse effect . This result was in line with Kowdley, et al., (2014). Who recorded that SOF/DAC/RBV given for 12 weeks resulted in $95 \% \mathrm{SVR}$ in 21 genotype 4 patients. Also these results were in agreement with Black\& Hawks, (2010) who found that the combination of SOF /DAC/RBV treatment was tested in large-scale clinical trials, resulting in SVR rates of more than $90 \%$ in patients with genotype 1 infection. But this was not agreeing with Dore, Foster. (2014). who reported that the SVR rate was significantly higher among cirrhotic patients in the 24-week treatment group than in the 12-week group (95\% vs. $88 \%$ ).

The current study revealed a great lack of patient's knowledge as regard to liver cirrhosis pre implementation of the nursing intervention either in both study and control groups. The majority of patients of study and control groups were having an unsatisfactory knowledge score levels in pre -test, This finding could be attributed to lack of patient's education about liver cirrhosis and the majority of study and control groups were illiterate and from rural area .

The result of the present study revealed that, the majority of study group patients after implementation of the nursing intervention were following the instructions given to them about therapeutic regimen, the food allowed and avoided food, and instructions about indicated and contraindicated medications. These results were in line with Weheida, et al., (2009) who found that, after care implementation there was an improvement in compliance of study group patients to therapeutic regimen, this could be explained by the fact that patients were given instructions about medication, also instructions given about food allowed and food that should be avoided to avoid further threatening Complications. This result also, was in line with Jay \& Marks, (2013) who recorded that cirrhotic patients with ascites had great learning needs due to the poor knowledge about their condition and a low level of performing selfcare and prevention of life threatening hazards of liver cirrhosis.

In the current study after implementation of the nursing intervention, patient's knowledge levels were significantly improved. This findings supported by Hairon, (2008) and who reported that, education is the key to successful treatment of the disease, and the nurse plays role as patient educator. Patients and their families need accurate information about the disease and about the strategies to minimize its impact.

In the present study, patient's pre intervention denoted the vast majority of them lack any essential knowledge about their medication, action, dose, route, frequency, possible side effects and how to manage and were provided to cover all aspects of $\mathrm{HCV}$ (definition, causes, signs and symptoms, treatment, action, dose, route, frequency, side effects and how to deal with it) which eventually increase patients knowledge. The nursing intervention presented to patients had given a significant increase in their knowledge about DAAD based regimen. These results were consistent with Fareed, (2010) who showed a statistical significant difference between before and after conduction the nursing management protocol that indicates an improvement of patients total mean score of knowledge after intervention. Also this finding was consistent with that obtained by Elshiekh, (2013) who found that repetition teaching on patient medication have significantly increase their knowledge regarding dose, special precautions and possible side effects of drug.

The result of the present study revealed that, participation in the nursing intervention demonstrated a significant improvement in study group knowledge of treatment for $\mathrm{HCV}$ as compared to prior participation of study and control groups in the nursing intervention.

Findings may be informing for nurses to understand that, patient and family teaching is an important nursing role that may make the difference in the ability of the patient and family to adapt to chronic conditions. Well-informed, educated patients are more likely than uninformed patients to be concerned about their health and to do what is necessary to maintain it. They are also more likely to manage symptoms, recognize the onset of complications and seek health care early. Knowledge is the key to make informed choices and decisions during all phases of the chronic illness trajectory.

\section{Conclusion}

The Present study we can finally conclude that, designed nursing intervention for patient receiving DAADs for Treatment of Chronic Hepatitis C 
achieved its objective by improving patient health status and their knowledge of treatment for hepatitisC.

\section{Recommendations}

- The current study recommended replication of nursing intervention of this study on larger probability sample from different geographical areas and in different hospital settings to allow greater generalizability of the results.

- Education of public population through mass media, posters and awareness campaigns about risk factors and prevention method of chronic hepatitis.

- Conduct further research to develop a training program about viral hepatitis (C) and methods of prevention from it.

\section{References}

1- Alan F., (2015): chronic hepatitis C. Medical News Today; 113(5): 1312-1332.

2- Alavian S., Kabir A., Hajarizadeh B., Nayebpour M., Dorodi T., \& Baralle F., (2010): Preliminary report of Interferon Alfa $2 b$ in combination with Ribivirin for 48 weeks for treatment of Iranian patients with chronic hepatitis $\mathrm{C}$.

3- American association for the Study of Liver Diseases (AASLD), (2012): Recommendations for testing, management, and treating hepatitis $\mathrm{C}$. When and in whom to initiate HCV therapy? Clin Gastroenterol Hepatol; 23: 45-62.

4- Bifano. M., Adamczyk. R, \& Hwang. C., (2015): Daclatasvir pharmacokinetics in healthy subjects: no clinically relevant drug-drug interaction with either cyclosporine or tacrolimus. 64th Annual Meeting of the American association for the Study of Liver Diseases (AASLD); 11: 34-37.

5- Black, J., \& Hawks, J., (2010): MedicalSurgical Nursing, Clinical Management for Positive Outcomes. J Hepatol; 43: 102-115.

6- Centers for Disease Control \& Prevention (CDCa), (2014): Prevention and Control of Infections with Hepatitis Viruses in Correctional Settings, [cited 2014 Aug 27]. Update by (AASLD the American Association for the Study of Liver Diseases, Viral Hepatitis Prevention, Screening, and Treatment; 4(3): (34-52). Available http://www.cdc.gov/hepatitis/Statistics.

7- Christopher F., (2011): A Critical Nursing Challenge Patients with End-Stage Liver Disease. Nursing Times; 21: 63-68.
8- Bartenschlager R., Lohmann V., \& Penin, F., The molecular and structural basis of advanced antiviral therapy for hepatitis $\mathrm{C}$ virus infection. Nat Rev Microbiol. 2013;11:482-496

9- El-Shikh A., (2013). The impact of a protocol of care on physical responses and compliance among patients with congestive heart failure. Unpublished Doctoral degree. Faculty of Nursing; Menoufyia university.

10- Fareed M., (2010): Dietary management in chronic renal failure patients and its effects on nutritional states, renal function tests and serum electrolytes. Unpublished Doctoral degree, Faculty of Nursing; Menoufyia University.

11- Goldberg E., \& Chopra S., (2014): Cirrhosis in adults, Etiologies, clinical manifestations, and diagnosis. Update. AC. eds; 14: 23-38. Accessed at: www.uptodate.com.

12- Dore G., Foster G., (2014): Simeprevir with pegylated interferon alfa 2 a plus ribavirin in treatment-naive patients with chronic hepatitis $\mathrm{C}$ virus genotype 1 infection )QUEST-1): a phase 3 , randomised, double-blind, placebo-controlled trial. Lancet; 384: 403-13.

13- Friedman, M., (2012): diagnosis and management of liver cirrhosis. Science; 32: 314334.

14- Hairon, N., (2008): New guidance on osteoarthritis focuses on patient education: the care and management of osteoarthritis in adults. http://www.nice.org.uk/CG59 .

15- Heneedy W., (2009): Study of the effect of nursing intervention on physical responses and compliance among patients with liver cirrhosis at National Liver Institute and Menoufyia university hospital. Unpublished Doctoral Thesis, Faculty of Nursing; Menoufyia University.

16- Jay W., \& Marks, M., (2013): hepatitis C treatments. Ann Intern Med; 5: 215-223.

17- Kowdley K., Lawitz E., Crespo I., Hassanein T., Davis M., (2014): Sofosbuvir with pegylated interferon alfa-2a and ribavirin for treatmentnaive patients with hepatitis $\mathrm{C}$ genotype-1 infection (ATOMIC): an open-label, randomised, multicentre phase 2 trial. Lancet; 381(9883):2100-7.

18- National Institute for Health \& Clinical Excellence (NICEa) (2012): Final Appraisal Determination - Telaprevir for the Treatment of Genotype 1 Chronic Hepatitis C. London. Available at www.nice.org.

19- van der Meer A., Veldt B,and Feld J., (2012): Association between sustained virological response and all-cause mortality among patients 
with chronic hepatitis $\mathrm{C}$ and advanced hepatic fibrosis. JAMA; 308: 2584-2593.

20- Weheida, S., Mohsen, M., Bahenasy, A., Shehata, A., \& Heneedy, W., (2009): Effect of protocol of care on clinical outcomes of patients with liver cirrhosis, Bull. Alex. Fac. Med. 45 No.3.

21- World health organization (WHO), (2012): prevention and control of viral hepatitis infection: frame work for global action. JAMA. Available at www.who.int/topic/hepatitis. 